\section{Discussion}

High platelet counts are rarely found in babies, and conditions associated with them have been reviewed (Addiego et al., 1974). The thrombocytosis in this patient was ciiscovered at the same time as a subarachnoid and intraventricular haemorrhage and a gross coagulopathy, and how these relate to each other is not certain. A likely sequence of events is that the coagulopathy allowed bleeding which provoked an unusually pronounced reactive platelet increase. If the high platelet count was the cause of bleeding, as paradoxically can occur in some myeloproliferative disorders, the coagulopathy would have to have been coincidental, which seems improbable.

Infantile central nervous system disease associated with thrombocytosis alone has been recorded by Sanyal et al. (1966) and Huttenlocher and Smith (1968) and has been implicated as being causally related (by precipitating cerebral thrombosis) as the high platelet count was seen to precede an acute hemiplegia in one case (Huttenlocher and Smith, 1968). In no previous report has a coincidental disorder of coagulation been noted.

Late vitamin $\mathrm{K}$ deficiency in infants has been described (Nammacher et al., 1970; Cooper and Lynch, 1979), and while the evidence for its existence in our case is entirely circumstantial, it is hard to offer an alternative explanation for such rapid permanent in vivo correction of a clinically obvious bleeding tendency associated with a prolonged prothrombin time in the absence of intravascular coagulation. There was no reason to suppose that the production of liver coagulation factors was impaired from any other cause, but no estimation of protein induced by vitamin $\mathrm{K}$ absence was made, which would have helped to clarify this aspect.

Quite why this child should be lacking vitamin $\mathrm{K}$ is hard to say, as breast feeding is the only reason to suppose a deficient supply. It must be acknowledged that it is possible some other factor provided permanent correction of the observed and apparently acquired bleeding tendency, but to define such a factor is not possible.

We thank Dr B. L. Priestley for referring this infant to us.

\section{References}

Addiego, J. E., Jr, Mentzer, W. C., Jr, and Dallman, P. R. (1974). Thrombocytosis in infants and children. Journal of Pediatrics, 85, 805-807.

Cooper, N. A., and Lynch, M. A. (1979). Delayed haemorrhagic disease in the newborn with extradural haematoma. British Medical Journal, 1, 164-165.

Huttenlocher, P. R., and Smith, D. B. (1968). Acute infantile hemiplegia associated with thrombocytosis. Developmental Medicine and Child Neurology, 10, 621-625.

Nammacher, M. A., Willemin, M., Harmann, J. R., and Gaston, L. W. (1970). Vitamin K deficiency in infants beyond the neonatal period. Journal of Pediatrics, 76, 549-554.

Sanyal, S. K., Yules, R. B., Eidelman, A. I., and Talner, N. S. (1966). Thrombocytosis, central nervous system disease, and myocardial infarction pattern in infancy. Pediatrics, 38, 629-636.

Correspondence to Dr J. S. Lilleyman, Department of Haematology, The Children's Hospital, Western Bank, Sheffield S10 2TH, Yorks.

\title{
Premature menarche without other evidence of precocious puberty
}

\author{
M. E. HELLER, JOHN DEWHURST, AND D. B. GRANT \\ Queen Charlotte's Maternity Hospital, and The Hospital for Sick Children, London
}

SUMMARY We describe 4 young girls with recurrent vaginal bleeding in the absence of other signs of precocious sexual development. Investigation showed low oestrogen levels in 2 of them, and basal gonadotrophins were in the upper part of the prepubertal range. We believe that the isolated early menstruation in these patients was possibly related to increased sensitivity of the endometrium to oestrogens.

Cyclical vaginal bleeding in the absence of other signs of secondary sexual development is rare and little has been written about the clinical and laboratory aspects of this condition. We describe 4 young girls seen at The Hospital for Sick Children because of recurrent menstrual bleeding; they had no other stigmata of precocious puberty or evidence of an underlying genital disorder.

\section{Case reports}

Case 1 (born 14.11.1960). When she was 10 months, this girl began to have episodes of vaginal bleeding which lasted for 2 or 3 days and recurred every 4 to 5 weeks. She had been born 2 weeks after the expected date of confinement, but her neonatal history and developmental progress were normal.

She was admitted to hospital at age 1.2 years for 
further investigation. Her height $(80 \mathrm{~cm})$ and weight $(11.4 \mathrm{~kg})$ were just above the 75 th centiles. No abnormality was found on examination. In particular, there was no breast development or pubic hair, no abnormal skin pigmentation, and examination under anaesthesia (EUA) was normal with no adnexal masses. A vaginal smear taken at the time of bleeding showed immature epithelial cells, but a further smear taken 2 weeks later showed definite evidence of oestrogenisation. Bone age was appropriate for chronological age, the urine 17oxosteroids were not raised $(0.4 \mu \mathrm{mol} / 24 \mathrm{~h} ; 0.1$ $\mathrm{mg} / 24 \mathrm{~h}$ ), and a slight increase in urine gonadotrophins was found on bioassay (2.1 HMG 20A units/24h).

Vaginal bleeding continued fairly regularly until age 3.4 years and then it began to lessen, finally stopping at age $4 \frac{1}{2}$. Urine gonadotrophins were undetectable $(<0.2$ HMG 20A units/24h) when re-estimated by bioassay at age $3 \cdot 2$ years.

When she was 10.8 years, vaginal bleeding recurred and took place almost daily. Because of continued bleeding she was readmitted at age $11 \cdot 3$ years. At that time she had early breast development but no pubic hair. Her height and weight were on the 50th centiles, her bone age was slightly advanced (12.5 years), and a vaginal smear showed definite evidence of oestrogenisation. Urinary oestrogen excretion was in the early pubertal range $(10 \cdot 5 \mathrm{nmol} / 24 \mathrm{~h} ; 3 \mathrm{ng} / 24 \mathrm{~h})$, as was urinary luteinising hormone (LH) excretion (6.5 IU/24h). Skeletal survey showed no evidence of fibrous dysplasia.

At age $12 \cdot 2$ years, her menorrhagia stopped and her periods became more regular. Secondary sexual development proceeded normally. When last seen at age 14.3 her menses were regular, pubertal development was well advanced, and her growth appeared complete.

Case 2 (born 13.4.1973). This girl, who was born after a normal pregnancy, began to have vaginal bleeding when she was aged about 18 months. This occurred every 28 days and lasted for up to 7 days with occasional intermenstrual spotting. She complained of abdominal pain before the onset of each episode of bleeding, but was otherwise in good health.

She was admitted for investigation at age $3 \frac{1}{2}$ years. Her height $(92.8 \mathrm{~cm})$ and weight $(13.4 \mathrm{~kg})$ were on the 50th centiles. There was no palpable breast tissue or pubic hair, and the vulva appeared infantile. She had no abnormal skin pigmentation. Investigations showed that the bone age was slightly retarded (2 years) and no evidence of fibrous dysplasia was seen on $x$-rays of the skull and long bones. Urinary LH $(2.9 \mathrm{IU} / 24 \mathrm{~h})$ and FSH $(2 \cdot 1 \mathrm{IU} / 24 \mathrm{~h})$ excretion were within the normal range for age, as were serum $\mathrm{LH}(2 \cdot 0 \mathrm{mIU} / \mathrm{l})$ and FSH (1.0 mIU/l). Plasma oestradiol was undetectable $(<0 \cdot 1 \mathrm{pmol} / \mathrm{l} ;<0.03 \mathrm{pg} / \mathrm{ml})$. EUA showed a small uterus with no adnexal masses, and cystoscopy was normal.

The patient had an episode of vaginal bleeding soon after the EUA, but when last seen at age $4 \cdot 1$ years there had been no further bleeding or other symptoms.

Case 3 (born 28.11.1974). This girl was seen when she was 2.9 years because of 7 episodes of vaginal bleeding since age $2 \cdot 2$ years. Her health and development until this had been normal. On examination, her height $(89.6 \mathrm{~cm})$ and weight $(12.6 \mathrm{~kg})$ were near the 50th centiles. No breast tissue was palpable and there was no pubic hair. The vulva appeared infantile and no pelvic masses were palpable on rectal examination. There was no abnormal pigmentation. Investigation at age 3.4 years showed a bone age between 3 and $3 \frac{1}{2}$ years and no evidence of fibrous dysplasia on skeletal survey. No hypothalamic or other brain abnormality was found on CAT. Her urinary LH excretion $(1 \cdot 1 \mathrm{IU} / 24 \mathrm{~h})$ and serum LH $(1.0 \mathrm{mIU} / \mathrm{l})$ were appropriate for her age, and there was no significant rise in serum $\mathrm{LH}$ after injection of $100 \mu \mathrm{g}$ luteinising hormone-releasing hormone (LRH). In contrast, urinary FSH excretion was slightly raised (3.4 IU/24h) and after injection of $\mathrm{LRH}$, there was a pronounced rise in serum FSH from 1.7 to $33.0 \mathrm{mIU} / 1$ after 60 minutes. Urinary total oestrogen excretion was $3.5 \mathrm{nmol} / 24 \mathrm{~h}$ (1 ng/24h).

Case 4 (born 18.2.1975). This girl began having vaginal bleeding when she was 3 months; it occurred at intervals of between 30 and 32 days, lasted for 2 or 3 days, and was preceded by up to 10 days of irritability and feeding difficulties. She had been born 2 weeks after term, but her health and developmental progress had been normal. When she was older, she complained of abdominal pain before each episode of bleeding.

When she was 2 years she was admitted to another hospital where an EUA was normal. As her bleeding continued, she was referred to The Hospital for Sick Children for further investigation. When seen at age 2.9 years, her height $(93.3 \mathrm{~cm}$; 75th centile) and weight (13.4 kg; 50th centile) were normal. There was no breast development or pubic hair, and the vulva appeared infantile. Rectal examination was normal and there was no abnormal skin pigmentation.

Investigations showed a slightly retarded bone age (2 years), serum LH $(2 \cdot 8 \mathrm{mIU} / \mathrm{l})$ and FSH $(2 \cdot 1$ $\mathrm{mIU} / \mathrm{l})$ were in the upper prepubertal range. There 


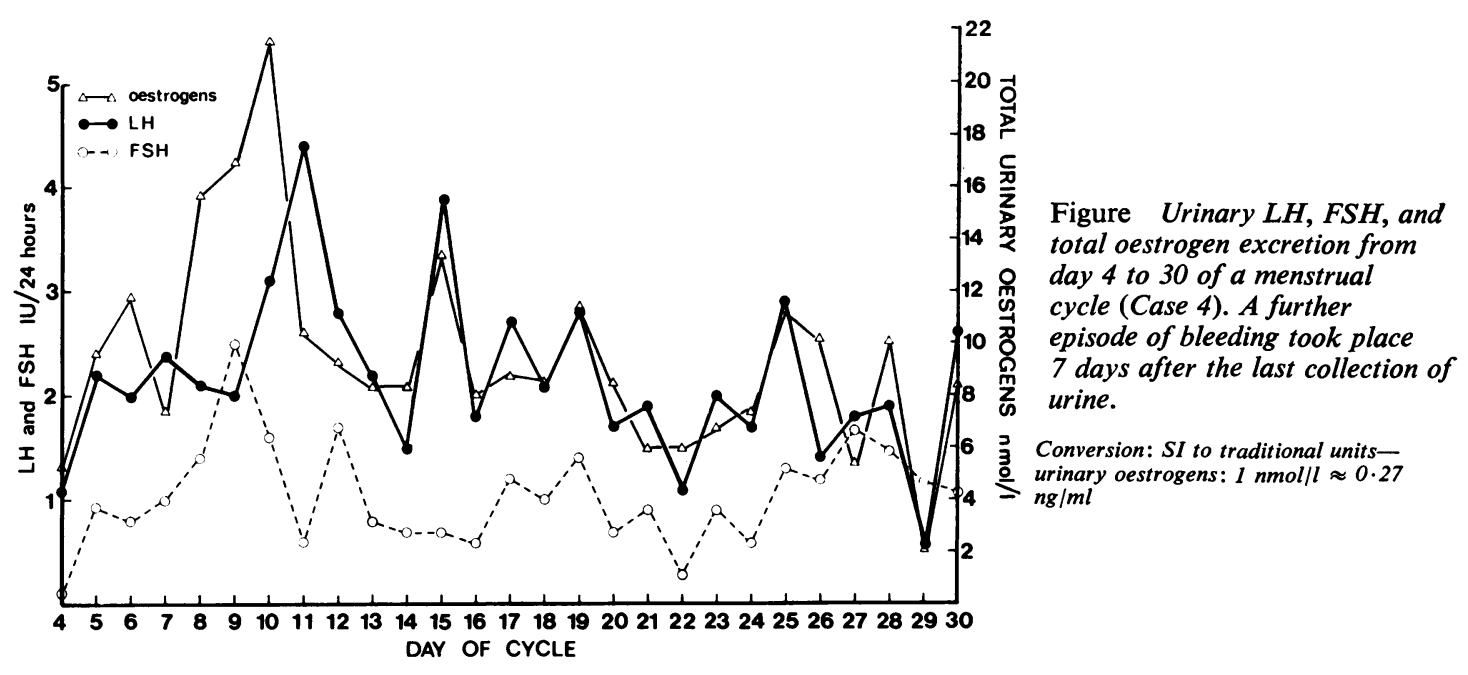

was no evidence of fibrous dysplasia on $x$-rays of the long bones.

Serial 24-hour collections of urine were carried out by the girl's mother at home. The collections were started on the 4th day after onset of bleeding and a further episode of bleeding took place 7 days after the collection period ended. The results for total urinary oestrogens, LH, and FSH excretion are shown in the Figure. While total urinary oestrogen excretion was generally low, an apparent peak of excretion took place on the 7th day of the collection (10th day of cycle). The next day, there appeared to be a small peak of LH excretion (4.3 IU/24h), with a possible further peak (3.9 IU/24h) 5 days later. Urinary FSH excretion was low throughout the period of collection.

\section{Discussion}

Our 4 cases are very similar to a case described by Blunck et al. (1967) in a review of transient sexual precocity. Their patient had recurrent menstrual bleeding which was not associated with other signs of secondary sexual development and she subsequently developed normally. In his textbook, Huffman (1968) described 2 such patients and referred to their benign clinical course. Similarly, our Case 1 menstruated fairly regularly between ages 10 months and 3.4 years and she subsequently had normal secondary sexual development after an initial period of menorrhagia. Our other 3 patients menstruated for between $1 \cdot 2$ and 2.7 years without other stigmata of precocious puberty, such as accelerated growth and bone maturation.

In a proportion of cases with precocious puberty, menstrual bleeding may be the first clinical mani- festation. For example, Sigurjonsdottir and Hayles (1968) found that 5 out of 54 girls with precocious puberty presented with bleeding between ages 6 months and $1 \cdot 9$ years. Further evidence of secondary sexual development occurred within 2 months to $1 \cdot 8$ years.

Menstrual bleeding is often the first sign of precocious puberty in the McCune-Albright syndrome, in which it is associated with abnormal skin pigmentation and fibrous dysplasia of bone. While in none of our Cases 1-4 was there abnormal skin pigmentation, we have seen 2 girls with a formefruste of McCune-Albright syndrome and no abnormal skin pigmentation. The first of these girls started to menstruate at age 6 weeks and the second at age 5.9 years. Initial $x$-rays were normal in both girls and radiological evidence of fibrous dysplasia did not develop until ages 7 and 9 years respectively. It is therefore possible that fibrous dysplasia may later become apparent in Cases 1-4.

In at least one patient, a local genital lesion was initially suspected as the cause of vaginal bleeding. Although a vaginal foreign body may present with bleeding, this does not show the cyclic pattern described above and usually causes a purulent vaginal discharge, which was not present in any of our patients. Genital neoplasms-such as botryoid sarcoma or hormonally active ovarian tumoursare rare causes of vaginal bleeding in childhood and were excluded by physical examination in our patients. Ingestion of oestrogen was suspected as a cause of the bleeding, but this was denied by the girls' mothers. In addition, the episodic nature of the bleeding and the absence of breast development virtually exclude this possibility. 
We have no good explanation for the early menstruation in our patients, but believe that it may be due to increased sensitivity of the endometrium to circulating levels of oestrogens which are too low to produce breast development. Certainly, the oestrogen values obtained in 2 of the patients were far below the levels found in normal ovulatory cycles. Case 4 apparently had a peak of urinary $\mathbf{L H}$ excretion on the 11th day of one of her menstrual cycles which was preceded by a peak of urinary oestrogen excretion on the previous day. The brisk rise in FSH after LRH stimulation in our Case 3 is surprising and is not in keeping with the very modest basal FSH levels found in 2 of the other cases. Further studies are obviously needed to establish whether this pronounced rise in FSH after LRH is a consistent feature in girls with early isolated menstruation.

We thank our colleagues for referring their patients for investigation.

\section{References}

Blunck, W., Bierich, J. R., and Bettendorf, A. (1967). Uber Fruhreife. III. Mitteilung. Idiopathische Pubertas praecox, temporäre Fruhreife und prämature Thelarche. Montasschrift für Kinderheilkunde, 115, 555-563.

Huffman, J. W. (1968). The Gynecology of Childhood and Adolescence, p. 352. Saunders: Philad elphia.

Sigurjonsdottir, T. J., and Hayles, A. B. (1968). Precocious puberty. A report of 96 cases. American Journal of Diseases of Children, 115, 309-321.

Correspondence to Dr D. B. Grant, The Hospital for Sick Children, Great Ormond Street, London WC1N 3JH.

\section{A boy with low-TSH hypothyroidism}

\section{P. J. SMAIL, T. E. ISLES, AND R. S. ACKROYD \\ Departments of Child Health and Biochemical Medicine, Ninewells Hospital and Medical School, Dundee}

SUMMARY A case of long-standing mild hypothyroidism is described. This was caused by partial TSH deficiency probably of hypothalamic origin, with no other pituitary hormone deficiencies, although with a decreased response of FSH and LH to LHRH.

Low thyroid-stimulating hormone (TSH) hypothyroidism of hypothalamic or pituitary origin is usually accompanied by other pituitary hormone deficiencies (Kaplan, 1975), isolated TSH deficiency in childhood having been described in only one report since the advent of modern TSH assays (Miyai et al., 1971). We report a case of low-TSH hypothyroidism in a child without evidence of other pituitary deficiencies although with decreased response of luteinising hormone (LH) and folliclestimulating hormone (FSH) to luteinising hormonereleasing hormone (LHRH).

\section{Case report}

A 6-year-old boy was admitted with a febrile illness. $\mathrm{He}$ was noted to have a deep voice, a protuberant abdomen, and an exaggerated lumbar lordosis. His height was on the 25th centile. He had not developed his first tooth until age 13 months and was said always to have been intolerant of cold. Serum thyroxine (T4) was $42 \mathrm{nmol} / \mathrm{l}(3 \cdot 2 \mu \mathrm{g} / 100 \mathrm{ml})$. Our laboratory mean is $110 \mathrm{nmol} / 1(8 \cdot 5 \mu \mathrm{g} / 100 \mathrm{ml})$ and range $\pm 2 \mathrm{SD}$ $75-145 \mathrm{nmol} / \mathrm{l}(5 \cdot 8-11 \cdot 2 \mathrm{mg} / 100 \mathrm{ml})$.
Other thyroid function studies included serum triiodothyronine (T3) $2 \cdot 1 \mathrm{nmol} / \mathrm{l}(1 \cdot 37 \mu \mathrm{g} / 100 \mathrm{ml})$, T3 index $109 \%$, free T4 index 39 , and TSH $<0.6$ $\mathrm{mU} / 1$. Antithyroid-cytoplasmic antibody (by fluorescent antibody technique) and antithyroglobulin antibody (by tanned red cell test) were negative. A ${ }^{99}$ technetium scan showed a normally placed thyroid gland. The responses of serum TSH, T4, T3, T3 index, and free T4 index to an IV dose of $200 \mu \mathrm{g}$ thyrotrophin-releasing hormone (TRH) are shown in the Table. Serum TSH increased to a maximum of $5.2 \mathrm{mU} / 1$ at 20 minutes. Bone age was $3 \cdot 3$ years at a chronological age of $6 \cdot 3$ years (Tanner Whitehouse) and skull $x$-ray was normal. $X$-ray of the hips showed advanced changes of Perthes's disease bilaterally. His intelligence was within the normal range although he was having coaching at school for reading and arithmetic.

After $0.25 \mathrm{mg}$ tetracosactrin IM, serum cortisol rose from $343 \mathrm{nmol} / 1(12 \cdot 3 \mu \mathrm{g} / 100 \mathrm{ml})$ to 723

Table Response to an intravenous dose of $200 \mu \mathrm{g}$ thyrotrophin-releasing hormone

\begin{tabular}{|c|c|c|c|c|c|c|}
\hline & \multicolumn{4}{|c|}{ Time (min) } & \multicolumn{2}{|c|}{ Laboratory } \\
\hline & 0 & 20 & 60 & 180 & Mean & Range $\pm 2 S D$ \\
\hline $\begin{array}{l}\text { TSH (mU/1) } \\
\text { T4 (nmol/1) } \\
\text { T3 (nmol/1) } \\
\text { T3 uptake \% } \\
\text { Free T4 index }\end{array}$ & $\begin{array}{l}3 \cdot 5 \\
58 \\
2 \cdot 0 \\
106 \\
55\end{array}$ & $\begin{array}{l}5 \cdot 0 \\
69 \\
2 \cdot 1 \\
109 \\
63\end{array}$ & $\begin{array}{l}2 \cdot 4 \\
47 \\
2 \cdot 1 \\
104 \\
45\end{array}$ & $\begin{array}{l}1 \cdot 7 \\
56 \\
2 \cdot 2 \\
105 \\
53\end{array}$ & $\begin{array}{l}-110 \\
1.7 \\
105 \\
103\end{array}$ & $\begin{array}{l}0-5 \\
75-145 \\
1 \cdot 0-2 \cdot 4 \\
97-113 \\
70-135\end{array}$ \\
\hline
\end{tabular}

Conversion: SI to traditional units - thyroxine: $1 \mathrm{nmol} \approx 0.077 \mu \mathrm{g} / 100$ $\mathrm{ml}$, triiodothyronine: $1 \mathrm{nmol} / 1 \approx 0.65 \mu \mathrm{g} / 100 \mathrm{ml}$. 